\title{
Teacher-Pupil Relationship in Implementing Modern Teaching Technologies
}

\author{
Huseyn Mirzayev \\ Ministry of Education, Azerbaijan Republic
}

\begin{abstract}
In the article, the features of using modern teaching tecnologies are investigated and results are revealed. The establishment of teacher-pupil relationships based on comfortable mutual trust and equal rights is the direct effect of proper and expedient use of innovative training technologies. Teaching technologies' features are explored, experiment examples are listed, and all these results are analysed in this article. In the article, modern teaching technologies' characteristic features are explored and the need of these features in teaching process with the teacher-pupil relationship is substantiated. Some conclusions were made to analyse all these points.
\end{abstract}

Keywords: modern teaching technologies, typical characteristics, co-operations, teacher-pupil relationships, age characteristics

\section{Introduction}

Globalization process in the world made the use of modern teaching technologies necessary. Not only the importance of the use of modern teaching technologies but the analysis and discussion of the name also became necessary.

Modern teaching technologies' features may be classified in the following way:

(1) Involving teacher and pupil in an creative activity;

(2) Passing simple and common skills to learners in useful activities during the communication with them;

(3) Close co-operation between teacher and pupil and among pupils and persistance of two persons' relationship;

(4) Using active and didactic games in purpose and arranging free and healthy phsycological atmosphere and social equality in the classroom;

(5) Performing the expedient presentations helping to the formation and development of creative thinking of pupil $[3,10]$.

Involvement of teachers and pupils in the intensive creative activities is the main point to arrange the quality of the lesson. Existence of the creative atmosphere shows the teacher's activity in the classroom.

Passing simple and common skills to the pupils is the result of the teacher's activity. Knowledge is the fund, base. But dead fund is not useful. Success of teacher is to change this fund into the skills $[1,26]$.

Co-operation between teacher and pupil and among pupils has always been the theme for discussions. It is obvious that useful and correct relationships lead to good results. Relationships appear in two directions: teacher-pupil and pupil-pupil $[4,32]$.

Huseyn Mirzayev, senior consultant, M.A., The Education Sector Development Programs, Azerbaijan Republic. 
These directions improve in connection with each-other and as sequel of one-another.

At this point, personal qualities coming from families are also important. Sometimes teachers have difficulties in treating the pupils influenced by the problematic families and controlling their relationships with other pupils $[2,28]$.

It is known that when using modern teaching technologies, dynamic activities take place in the process. It is pupil's need. Depending on the age, active movements become more in the behavior of pupils. It is a natural process though it must be managed. Experiments show that using modern teaching technologies in the teaching process may cause chaos, too. But it is not the reason to restrict the activity and freedom of pupils. If the main aim of modern education is "personality formation" so this person must be free in thoughts, having skill to say own point of view independently. It is clear that these qualities cannot be established in abandoned atmosphere. According to experiences, management of the classroom in right way and systematically is also based on the personal qualities and character of the teacher [1,27].

All these mentioned show that use of innovative teaching technologies in the teaching process demands much effort. As society is not ready for this, use of innovative teaching technologies is not accepted. Specialists investigate problems arising from differences between the previous system and new approach. Development in education system is also the same. After investigating features, different qualities, advantages, and risks of every innovation, it is easy to use it.

\section{Methods}

Use of modern teaching technologies means to teach pupils as followings:

(1) Thinking and presenting thoughts independently;

(2) Making conclusion;

(3) Sharing and analysing knowledge;

(4) Self-assessment;

(5) Being ready for co-operation;

(6) Listening and showing respect to others' thoughts;

(7) Proving own points of view with arguments;

(8) Having creative thinking;

(9) Co-operating with others to solve definite problems [3,9].

Thinking independently is one of the main qualities formed in teaching process. It is not formed by teaching only one or group of subjects. At this point, reading culture of children is very important. Reading and analysing literature improves the skills independently thinking and presenting thoughts [6,31].

Use of modern teaching technologies in teaching process helps to teach pupils new skills and modern qualities. But pupils have difficulties in sharing their new knowledge and skills. According to experiences, sharing helps pupils to form attitude towards his surroundings [4, 12].

Self-assessment is formed by introspection and self-analyse. So self-assessment is a complex process. A person looks at himself and differs. Who he differs himself with depends on his personal thoughts, qualities, and attitude towards the others. So a person himself chooses the one to be differed with. Self-assessment has an infuence on the personality and activity of a man. Mutual attitude of pupils, achievements, and loses depend on self-assessment $[1,18]$. 
Self-assessment meets in one personality: He estimates himself. In other words we can say it is the "Second Me" or internal report. But there may be some subjective criterion, that is the opinion of the estimated person. And it depends on how critically and responsibly he estimates himself $[5,16]$. Importance of the following features appeared in analysing self-assessment.

(1) Comparing specialities between "real me" and "ideal me" and suiting each-other is the main condition for person's phsycological health;

(2) People, growing, have tendency to be rich and change their ideals and so their standards also change. We have to know with whom they compare themselves in order to determine the estimated standard of pupil. By this way we have chance to analyse his "ideal me". Because these standards have special place in "ideal me";

(3) Every person has his own valuation system. On the one hand, he estimates himself, on the other hand, he is estimated by the group he belongs to. It is a reality that a person behaves like the surrounding expects him to. That is called expected behaviour and assessment made by the observing group shows the reallity $[2,14]$.

Phsycological experiments let us devide the self-assessment into three levels. In adequate self-assessment pupil can estimate himself rightly. If his ability must be estimated highly, he does it.

(1) It is determined that if pupil's "real me" corresponds to his "ideal me", he estimates himself highly. It comes out of two things: (a) Pupil really tries to be ideal (chance also play role) and (b) pupil feels himself in this level wrongly;

(2) When pupil feels inconsistent between "real me" and "ideal me", he estimates himself much lower than he is. Sometimes such situations make people lose trust in themselves or even depressed [5, 29]. If a pupil can estimate himself rightly, it shows his satisfactory phsycological position. Such pupils act systematically and have possibilities to achieve their aims. These pupils have strong character and are not influenced by others;

(3) Non-adequate self-assessment of pupil is a wide spread case nowadays. This case is engaged with different factors. These factors must be determined and solved by the help of the teaching process participants $[2,11]$. The experiences say that all these are the result of depression in the person's phsycology. But what is the reason of depression? There are some reasons. Happy or unhappy and complete or devorced families, families with single or many children, the relations in the family, pupil's status in the school society, his physical and phsycological development-influence on the the self-assessment of a pupil shows how adequate it is $[1,23]$.

\section{Problematic Situation}

The main condition for the use of teaching technologies in teaching process is communication. Communication is worth not only in the teaching process but also in all society. The lack of communication is one of the main problems nowadays.

It has own reasons. The development of education depends on the aimful work of participants of teaching process. Communication is very important at this point. If teaching process is based on the modern teaching technologies in class, pupils have to communicate, share their thoughts and opinions, and take part in different debates. But whether pupils are ready for such situations or not is still a difficult and actual problem. Sometimes teachers have problems in it. It is difficult to control, lead, and teach pupils with different characters and different family traditions in one class with the modern teaching technologies. 


\section{Results}

A poll conducted in several schools in Baku in teaching the teacher-student relationships and communication with the use of modern teaching technologies importance of the issue is once again revealed. Results are given below:

Table 1

Students With a Survey

\begin{tabular}{|c|c|c|c|c|c|c|c|c|}
\hline No. & Questions & Total & Yes & $\%$ & No & $\%$ & Partially & $\%$ \\
\hline 1 & Are there teachers who speak about own problems at the lesson? & 67 & 10 & $15.00 \%$ & 24 & $37.00 \%$ & 33 & $48.00 \%$ \\
\hline 2 & Do the teachers use life examples explaining their thoughts? & 67 & 49 & $73.00 \%$ & 0 & $0 \%$ & 18 & $27.00 \%$ \\
\hline 3 & Do your teachers use books much in teaching process? & 67 & 34 & $51.00 \%$ & 5 & $8.00 \%$ & 28 & $41.00 \%$ \\
\hline 4 & Do your teachers often get angry at the lesson? & 67 & 17 & $25.00 \%$ & 14 & $19.00 \%$ & 36 & $56.00 \%$ \\
\hline 5 & Do the teachers pay attention to special pupils in class? & 67 & 21 & $31.00 \%$ & 17 & $25.00 \%$ & 29 & $44.00 \%$ \\
\hline 6 & Are the teachers active in the class during the lesson? & 67 & 30 & $45.00 \%$ & 4 & $6.00 \%$ & 33 & $49.00 \%$ \\
\hline 7 & Do teachers use mimics to explain their thoughts? & 67 & 31 & $46.00 \%$ & 9 & $13.00 \%$ & 27 & $41.00 \%$ \\
\hline 8 & Are the problems arisen among the pupils solved immediately? & 67 & 30 & $45.00 \%$ & 5 & $7.00 \%$ & 32 & $48.00 \%$ \\
\hline 9 & Do your teachers use traditional methods of teaching? & 67 & 33 & $50.00 \%$ & 6 & $8.00 \%$ & 28 & $42.00 \%$ \\
\hline 10 & Are the pupils free to suggest their opinions in class? & 67 & 27 & $40.00 \%$ & 10 & $16.00 \%$ & 30 & $44.00 \%$ \\
\hline
\end{tabular}

Analysing the results of questionnaire, we see that using technologies in teaching process rightly is very important in teacher-pupil relations. Comparing the results in percent, we get the conclusion that there are not still enough teachers who can control the class according to modern circumstances.

Modern teaching technologies demand teacher's activity before the lesson and pupils' activity during the lesson. Use of these technologies is based on the mental activity and co-operetion among the participants of the teaching process. If modern teaching technologies are successfully used in teaching process, it results in development of pupils' creative thinking.

Great German pedogog Fridrix Frebel (1782-1852) shows that everything is improving in the nature and people are in this process. F. Frebel thought this as the main law of the being. And personality improves on the base of forces influencing his activity. Teaching process is main of these effects. Systematic development will be effective if the use of teaching technologies is done rightly $[6,26]$.

The main point of use of modern teaching technologies is to involve pupils in different kinds of activities. The aim is the work of pupils not to be done by teachers. It releases teacher's work. To involve pupils in the activity treats them too. Making real life situations at the lesson helps to achieve aims successfully.

\section{Discussions}

(1) Choosing suitable class for the use of modern teaching technologies makes teaching process more effective;

(2) Phsycological features of teching technologies also must be analysed side by side with the methodology of teaching technologies;

(3) Modern teaching technologies cause the lack of communication among the participants of the teaching process.

\section{Conclusion}

Using modern teaching technologies in teaching process will result in improving creative thinking of 
pupils. It is a great need to form personalities with high creative potential for developed society. In the article, this point takes special attention and some results have been made.

\section{References}

Agayev, S. S., Mehdizade, Z. M., \& Farajov, I. A. (1977). Age and educational psychology. Baku. Aliyev, R. (2004). Urgent issues of psychological services to the school. Baku. Aliyeva, H., \& Mamedov, U. (2014). Modern educational technologies. Baku. Aliyeva, Z. (2004). Pedagogy. Baku.

Gamzaev, M. (1991). Educational psychology. Baku.

Nazarov, A. (2012). Modern educational technologies. Baku. 